\title{
Study of Magnetic Vibration Absorber with Permanent Magnets along Vibrating Beam Structure
}

\author{
F. B. Sayyad and N. D. Gadhave \\ Mechanical Engineering Department, Genba Sopanrao Moze College of Engineering, Pune, Maharashtra 411045, India \\ Correspondence should be addressed to F. B. Sayyad; farooksayyad@rediffmail.com
}

Received 14 February 2013; Accepted 19 May 2013

Academic Editor: Mustafa Kemal Apalak

Copyright ( 2013 F. B. Sayyad and N. D. Gadhave. This is an open access article distributed under the Creative Commons Attribution License, which permits unrestricted use, distribution, and reproduction in any medium, provided the original work is properly cited.

\begin{abstract}
The vibration absorbers are frequently used to control and minimize excess vibration in structural system. Dynamic vibration absorbers are used to reduce the undesirable vibration in many applications such as pumps, gas turbines, engine, bridge, and electrical generator. To reduce the vibration of the system, the frequency of absorber should be equal to the excitation frequency. The aim of this study is to investigate the effect of magnetic vibration absorber along vibrating cantilever beam. This study will aim to develop a position of magnetic vibration absorber along the cantilever beam to adopt the change in vibratory system. The absorber system is mounted on a cantilever beam acting as the primary system. The objective is to suppress the vibration of the primary system subjected to a harmonic excitation whose frequencies are varying. It can be achieved by varying the position of magnetic vibration absorber along the length of beam. The advantage of magnetic vibration absorber is that it can be easily tuned to the excitation frequency, so it can be used to reduce the vibration of system subjected to variable excitation frequency.
\end{abstract}

\section{Introduction}

Dynamic vibration absorbers are used to reduce undesirable vibrations in many applications such as electrical transmission lines, helicopters gas turbines, engines, and bridges. Traditional treatment methods of vibration control that involve structural modifications are often time consuming and expensive. Some of them can be used as tunable vibration absorbers to control vibrations. Tunable dynamic vibration absorber which is simple to construct can be easily tuned to excitation frequency to minimize the vibrations and can be effectively used to minimize vibrations of structure. Absorber with variable frequencies can be used to minimize vibrations of structures having variable frequency drive. Dynamic vibration absorbers (DVAs) were first invented in 1909 by Hermann Frahm, and since then it has been successfully used to suppress wind-induced vibration and seismic response in buildings. In recent studies, interest has also been focused on the use of feedback and feedforward control systems and the synthesis of DVAs for multiple-degree-of-freedom systems. Igarasi et al. [1] have developed a magnetic dynamic vibration absorber with adjustable natural frequency, in these three permanent magnets arranged with opposite pole to each other. Repelling force between two magnets was used as spring constant. In 1993 they developed a dynamic vibration absorber using permanent magnets to suppress the vibrations of beam structures which was tuned to various frequency of beam by adjusting the distance between three rare-earth magnets. Nagaya and Sugiura [2] have developed the magnetic levitation actuator for obtaining a linear system. They investigate the nonlinear properties of spring constant. The restoring force due to the magnetic force is linearized by controlling the electric currents in the coil of electromagnets. Nagem et al. [3] have developed the electromechanical vibration absorber to suppress the vibration of simply supported beam, and they used the E shape magnet. Nagaya et al. [4] presented a method of vibration control for structures with consideration of higher modes of vibrations. In their method, the principle vibration mode is controlled by the use of autotuning antiresonance control of the tunable variable stiffness vibration absorber without damping, and higher modes are suppressed by the optimal vibration absorber with magnetic damper. Li and 
$\mathrm{Hu}$ [5] have presented numerical simulation of magnetic field design for damping thermocapillary convection in a floating half zone. Balamurugan and Narayanan [6] have developed smart constrained layer damping (SCLD) treatment to control the vibration of beams. SCLD design consists of viscoelastic shear layer sandwiched between two layers of piezoelectric sensors and actuator, and this composite bonded to a vibrating structure acts as a smart treatment. Hill and Snyder [7] have described the design of vibration absorber (dual mass vibration absorber) using FEA in ANSYS software to reduce structural vibrations at multiple frequencies with enlarged bandwidth. They have carried out experiments to control vibrations of panel having all sides' clamped boundary conditions and simply supported beam. They have shown that absorber could be used to provide local vibration attenuation on large electrical transformers. Bhave and Gupta [8] have designed and development active dynamic vibration absorber. Solenoid valves with plunger and spring arrangement was used to keep absorber mass fixed with beam. The absorber designed was best for those machines, which run at variable speeds but remain at particular speed for a considerable amount of time. Hashemi and Semercigil [9] have modeled a building as a cantilever beam. They have designed active moving mass damper and experimentally implemented it to control the first mode of vibrations. Then they have designed alternative pendulum control system and implemented it. Liu et al. [10] have developed a tunable electromagnetic vibration absorber whose stiffness is tunable online. The EMVA is capable of suppressing vibration of the primary system (simply supported beam) excited by harmonic force with variable frequency. Khazanov [11] has explained the effective and low-cost method to reduce the vibrations of pump over a wide operating speed range by installing a dynamic vibration absorber. Deng and Gong [12] have presented the application of magneto rheological elastomer to the vibration absorber. Moradi et al. [13] have designed the tunable vibration absorber to suppress chatter vibrations in boring operation in which boring bar is modeled as a cantilever Euler-Bernoulli beam instead of it being considered as single-degre-of-freedom system. The optimum values of the absorber parameters such as spring stiffness, absorber mass, and its position are determined using an algorithm based on mode summation method. Huang and Hung [14] have developed the piezoelectric vibration absorber. The absorber is made of a pair of piezoelectric sheets, attached to both sides of the plate, and closed electric circuits. One piece of the piezoelectric material serves as a sensor for detecting the motion of the plate. Another piece serves as an active dynamic absorber.

\section{Comments}

Traditional treatment methods of vibration control that involve structural modifications are often time consuming and expensive. Different methods are available to control vibration of beam, structures, and machineries. Some of them

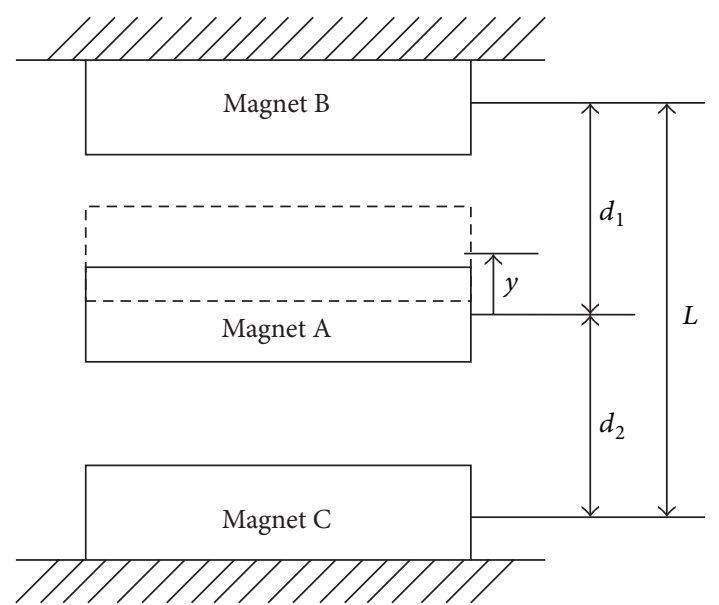

FIgURE 1: Arrangements of three cylindrical magnets.

can be used as tunable vibration absorbers to control vibrations. Magnetic dynamic vibration absorber which is simple to construct can be easily tuned by changing the distance between magnets to excitation frequency to minimize the vibrations and can be effectively used to minimize vibrations of structure. The aim of this study is to investigate the effect of magnetic vibration absorber along vibrating cantilever beam. This study will aim to develop a position of magnetic vibration absorber along the cantilever beam to adopt the change in the vibratory system.

\section{Theoretical Design of Absorber}

The magnetic vibration absorber proposed in this study is the same as the passive magnetic vibration absorber. It is made up of three permanent magnets with two poles facing each other set in front of each other as shown in Figure 1. A magnetic dynamic absorber uses repelling force of permanent magnets as restoring force (restoring force that acts on magnet $\mathrm{A}$ forming mass element of the absorber) and changes the natural frequency of absorber by changing the distance between magnets on both sides. Natural frequency of absorber can be changed on wider range by changing the distance between magnets.

For cylindrical magnets, relation between the distance between magnets and repelling force $F(d)$ is calculated by using

$$
F(d)=K d^{-n}
$$

where $K=1.5 * 10^{-3} \mathrm{NM}$ is the characteristic coefficient of repelling force and $n=3.022$ is the characteristic exponent of repelling force.

Distances $d_{1}$ and $d_{2}$ are obtained by solving the following equation:

$$
\begin{gathered}
k\left(d_{1}^{-n}-d_{2}^{-n}\right)+m g=0, \\
d_{1}+d_{2}=L .
\end{gathered}
$$


TABLE 1: Solution of simultaneous equation.

\begin{tabular}{lccccc}
\hline$L$ & $d_{1}$ & $d_{2}$ & $F\left(d_{1}\right)$ & $F\left(d_{2}\right)$ & $K_{e}$ \\
\hline 130 & 66 & 64 & 5.6202 & 6.168 & 548.57 \\
120 & 60.92308 & 59.0769 & 7.1582 & 7.856 & 756.42 \\
110 & 55.84615 & 54.1538 & 9.3142 & 10.219 & 1074.085 \\
100 & 50.76923 & 49.2308 & 12.418 & 13.629 & 1577.42 \\
90 & 45.69231 & 44.3077 & 17.077 & 18.739 & 2407.46 \\
80 & 40.61538 & 39.3846 & 24.375 & 26.751 & 3865.97 \\
70 & 35.53846 & 34.4615 & 36.5187 & 40.049 & 6617.169 \\
60 & 30.46154 & 29.5385 & 58.154 & 63.812 & 12296.85 \\
50 & 25.38462 & 24.6154 & 100.93 & 110.784 & 25613.30 \\
40 & 20.30769 & 19.6923 & 198.25 & 217.272 & 62826.5 \\
30 & 15.23077 & 14.7692 & 472.384 & 518.344 & 199774.33 \\
\hline
\end{tabular}

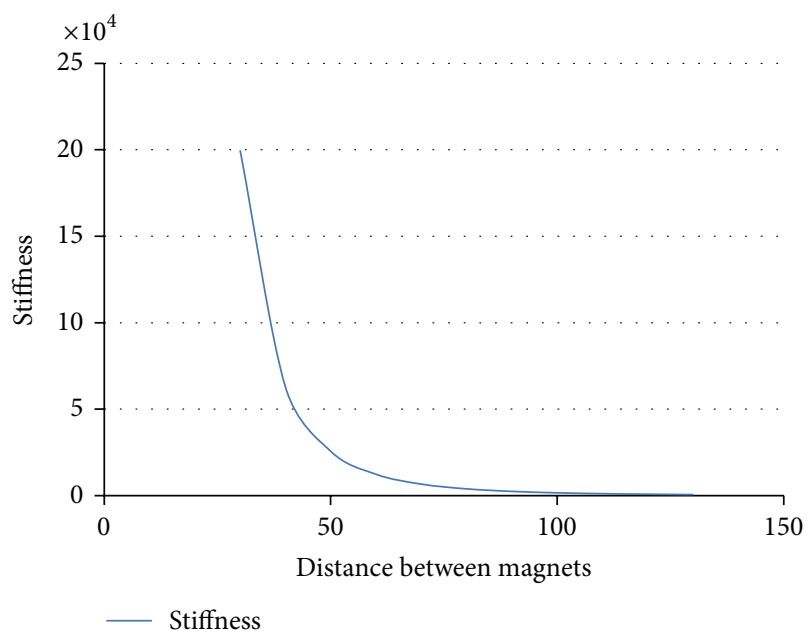

FIGURE 2: Graph of stiffness versus distance between magnets.

The stiffness of absorber is calculated with the help of the following equation (5)

$$
K_{e}=k n\left\{d_{1}^{-(n+1)}+d_{2}^{-(n+1)}\right\} .
$$

Results of the above equations are given in Table 1.

Figure 2 shows the graph of stiffness versus distance between magnets.

The frequency of absorber is calculated with the help of the following equations:

$$
\begin{gathered}
\omega n 1=\sqrt{ }\left(\frac{K e}{m}\right), \\
f n 1=\frac{\omega n}{2 \pi} .
\end{gathered}
$$

Natural frequencies decrease with the increase in distance between magnets. Figure 3 shows the graph of natural frequencies versus distance between magnets.

The tunable absorber will be tuned to change the frequency from $0.8 f n$ to $1.2 f n$. So approximately frequency of absorber lies in between $34.08 \mathrm{~Hz}$ and $51.12 \mathrm{~Hz}$. Therefore, respective distance between magnets is selected as $70 \mathrm{~mm}$.

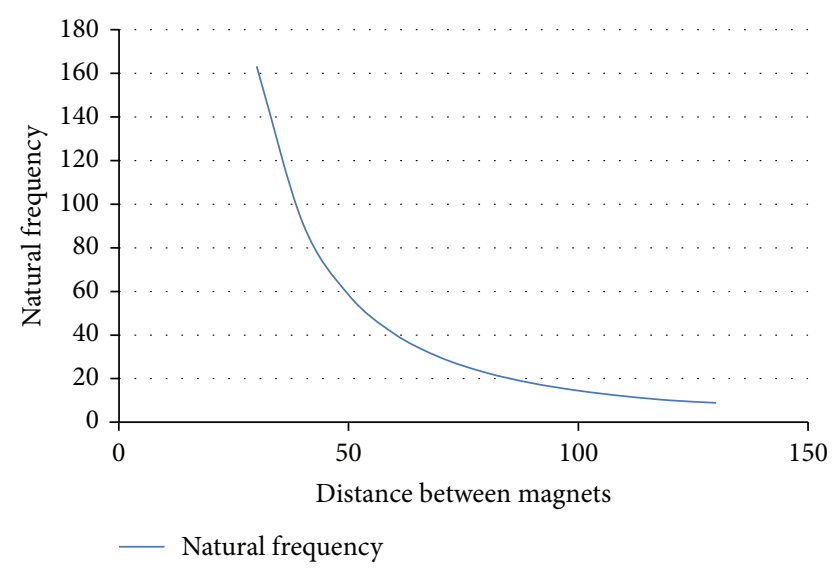

FIGURE 3: Graph of natural frequencies versus distance between magnets.

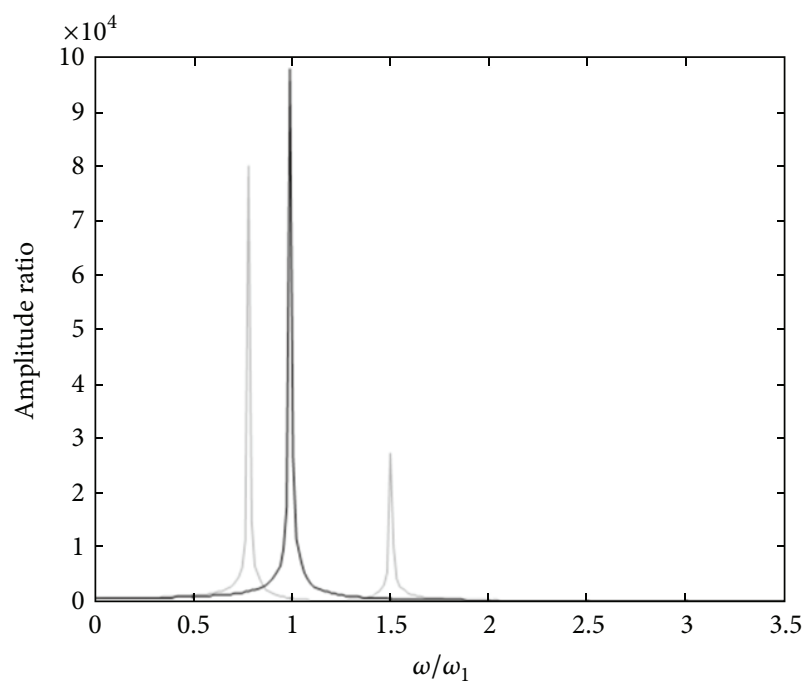

FIGURE 4: Frequency response of cantilever beam with tuned absorber.

The main system cantilever beam having mass $m_{1}$ and stiffness $k_{1}$ is coupled with secondary system having mass $m_{2}$ and stiffness $K_{2}$. The primary system is excited by harmonic force $F_{0} \sin (\omega t)$. The cantilever beam of dimensions length $=$ $0.544 \mathrm{~m}$, width $=0.05 \mathrm{~m}$, and height $=0.01 \mathrm{~m}$ made of steel is selected. The dimensionless frequency response curves for the main system and undamped absorber tuned to various excitation frequencies are shown in Figure 4.

The attenuation performance of undamped absorber is evident at $\omega / \omega_{1}=1$. The addition of properly tuned absorber will cause the system previously characterized by a single resonance to have two resonances. The two frequencies appear on either side of single resonance. The mass ratio $m_{2} / m_{1}$ plays an important part in determining if the absorber is effective. 


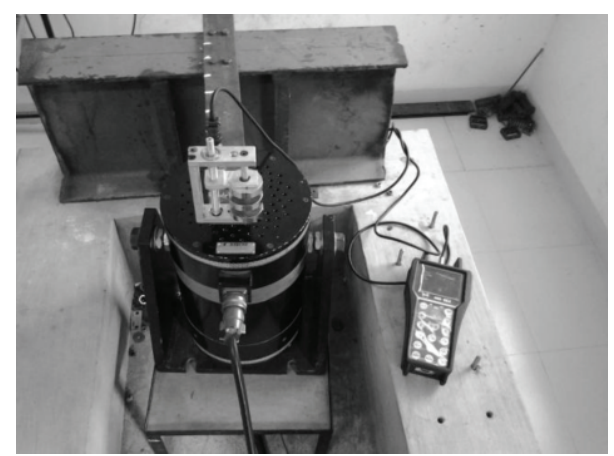

Figure 5: Experimental setup.

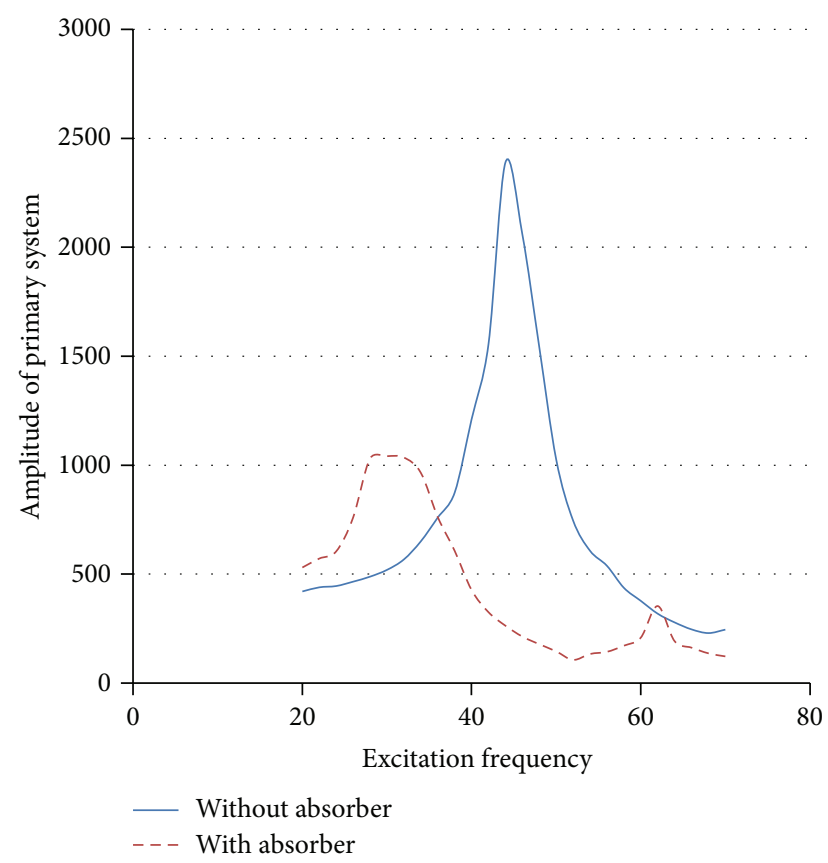

FIGURE 6: Graph of amplitude versus excitation frequency of beam with and without absorber.

\section{Experimental Studies}

The experiments are done on cantilever beam. One end of the beam is clamped to rigid support, and the absorber is clamped to the free end of the beam. Accelerometer is mounted on the beam as shown in Figure 5. The beam is excited with the help of the exciter. For the first set of readings, mass on rods of absorber is at its outermost position.

Excitation frequency is gradually increased and for each frequency amplitude of vibration of the main system is measured. Then, for the next set of readings, the position of magnetic vibration absorber along vibrating cantilever beam is changed. For this setup again, excitation frequency is gradually increased. Same procedure is repeated for a number of positions of the magnetic vibration absorber along the vibrating cantilever beam. Then, amplitude versus excitation frequency graph is plotted for different distances between magnets for cantilever beam which is shown in Figure 6.

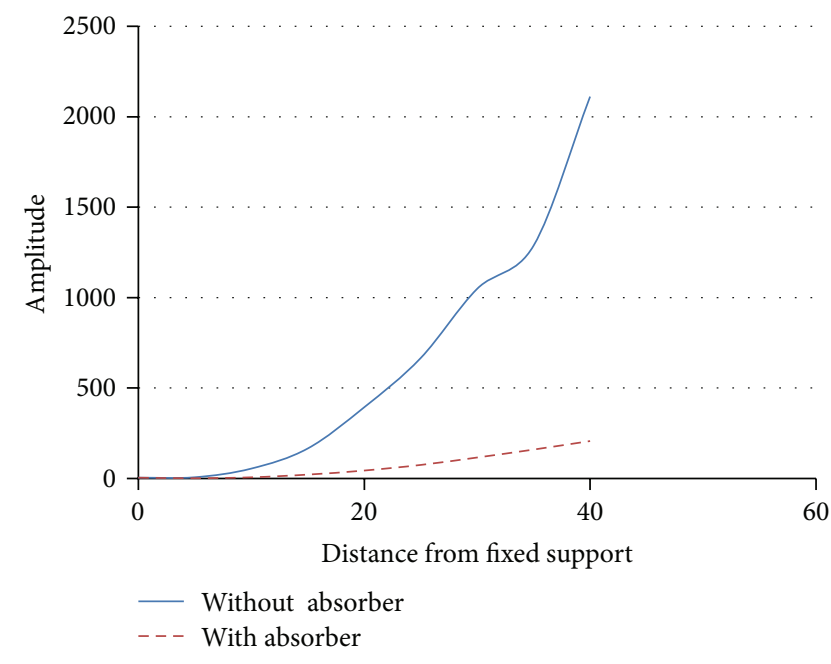

FIGURE 7: Response of beam with and without absorber along the length of beam. (Beam amplitude at $43 \mathrm{~Hz}$ frequency for $l=37 \mathrm{~mm}$ distance.)

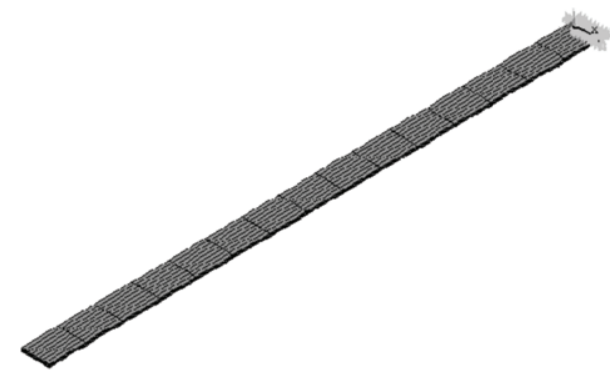

Figure 8: FEA mesh model of cantilever beam.

From Figure 6, it is clear that the amplitude of vibration is considerably minimized. Thus, the cantilevered magnetic absorber can be designed which is easy to construct. This magnetic absorber can be used as a tunable vibration absorber at multiple frequencies.

From Figure 7, it is clear that the absorber is more efficient at support position of beam at excitation frequency $43 \mathrm{~Hz}$, that is, at resonance frequency.

\section{Conclusion}

By using ANSYS software, the natural frequency of primary system and mode shapes have been studied. Theoretical and ANSYS values of frequencies are in close proximity. Natural frequencies of absorber were calculated by analytical method, and the effect of the distance between magnets on natural frequencies has been studied. It was observed that as distance between magnets was increased the natural frequencies decreased. The absorber is effective nearby resonance. There was a significant reduction in the amplitude of the primary system when the absorber was tuned at resonance, and amplitude of vibration is reduced from 2389 microns to 263 microns when the distance between magnets $L=$ $52 \mathrm{~mm}$. It was observed that as distance between magnets 
TABLE 2: First four natural frequencies of cantilever beam (FEA).

\begin{tabular}{lcccc}
\hline Sr. no. & 1 & 2 & 3 & 4 \\
\hline Frequency $(\mathrm{Hz})$ & 42.60 & 210.22 & 269.09 & 695.97 \\
\hline
\end{tabular}

was changed that is, tuned, there is a slight shifting of the peak. Effectiveness of absorber is checked on the cantilever beam. It is found that the designed absorber is very effective to reduce vibrations of beam when it is tuned to various excitation frequencies nearer to the natural frequency of cantilever beam. Also it is observed that the absorber is more efficient at the support position of beam (Table 2).

\section{Appendix}

Figure 8 shows the FEA mesh model of cantilever beam.

\section{References}

[1] S. Igarasi, K. Shibukawa, S. Nakatani, and H. sekito, "Study on dynamic vibration absorber using permanent magnet," Bulletin of the Faculty of Engineering, Hokkaido University, vol. 156, pp. 29-28, 1991.

[2] K. Nagaya and M. Sugiura, "Method for obtaining a linear spring for a permanent magnet levitation system using electromagnetic control," IEEE Transactions on Magnetics, vol. 31, no. 3, pp. 2332-2338, 1995.

[3] R. J. Nagem, S. I. Madanshetty, and G. Medhi, "An electromechanical vibration absorber," Journal of Sound and Vibration, vol. 200, no. 4, pp. 551-556, 1997.

[4] K. Nagaya, A. Kurusu, S. Ikai, and Y. Shitani, "Vibration control of a structure by using a tunable absorber and an optimal vibration absorber under auto-tuning control," Journal of Sound and Vibration, vol. 228, no. 4, pp. 773-792, 1999.

[5] K. Li and W. R. Hu, "Numerical simulation of magnetic field design for damping thermocapillary convection in a floating half-zone," Journal of Crystal Growth, vol. 222, no. 3, pp. 677684, 2001.

[6] V. Balamurugan and S. Narayanan, "Finite element formulation and active vibration control study on beams using smart constrained layer damping (SCLD) treatment," Journal of Sound and Vibration, vol. 249, no. 2, pp. 227-250, 2002.

[7] S. G. Hill and S. D. Snyder, "Design of an adaptive vibration absorber to reduce electrical transformer structural vibration," Journal of Vibration and Acoustics, Transactions of the ASME, vol. 124, no. 4, pp. 606-611, 2002.

[8] S. Y. Bhave and R. Gupta, "Design and development of active dynamic vibration absorber," Journal of the Institution of Engineers (India): Mechanical Engineering Division, vol. 84, no. 2, pp. 51-54, 2004.

[9] S. M. Hasmi and M. F. Golnaarghi, "Active control of wind induced building vibration using a linear coupling strategy," Asian Journal of Civil Engineering, vol. 4, pp. 35-53, 2003.

[10] J. Liu, K. Liu, and L. Liao, "Comparison of two auto-tuning methods for a variable stiffness vibration absorber," Transactions of the Canadian Society for Mechanical Engineering, vol. 29, no. 1, pp. 81-96, 2005.

[11] Y. Khazanov, "Dynamic vibration absorber-application with variable speed machines," Pumps and System, pp. 114-119, 2007.
[12] H.-X. Deng and X.-L. Gong, "Application of magnetorheological elastomer to vibration absorber," Communications in Nonlinear Science and Numerical Simulation, vol. 13, no. 9, pp. 1938-1947, 2008.

[13] H. Moradi, F. Bakhtiari-Nejad, and M. R. Movahhedy, “Tuneable vibration absorber design to suppress vibrations: an application in boring manufacturing process," Journal of Sound and Vibration, vol. 318, no. 1-2, pp. 93-108, 2008.

[14] Y. M. Huang and S. C. Hung, "Analytical study of an active piezoelectric absorber on vibration attenuation of a plate," Journal of Sound and Vibration, vol. 330, no. 3, pp. 361-373, 2011. 

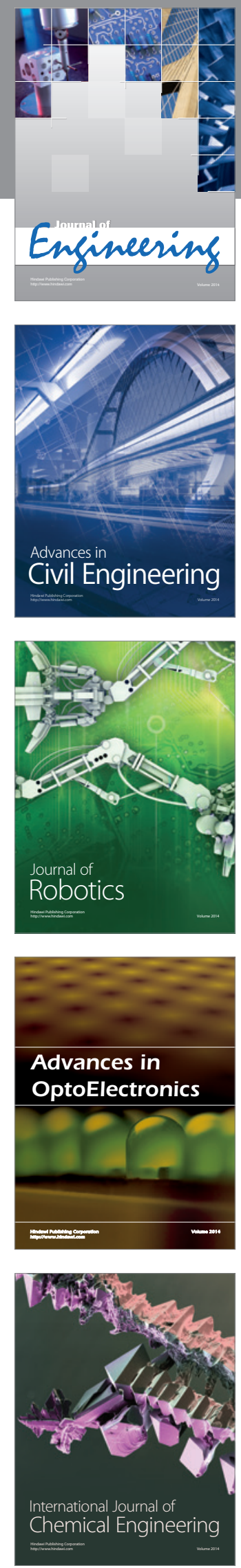

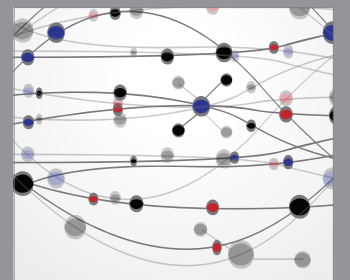

The Scientific World Journal
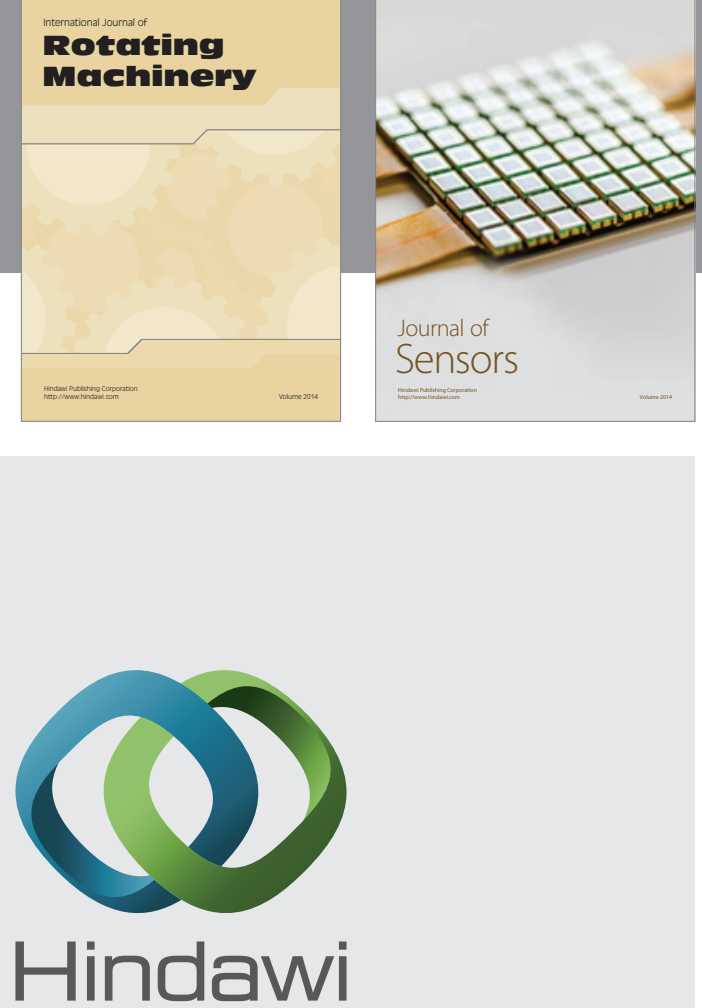

Submit your manuscripts at http://www.hindawi.com
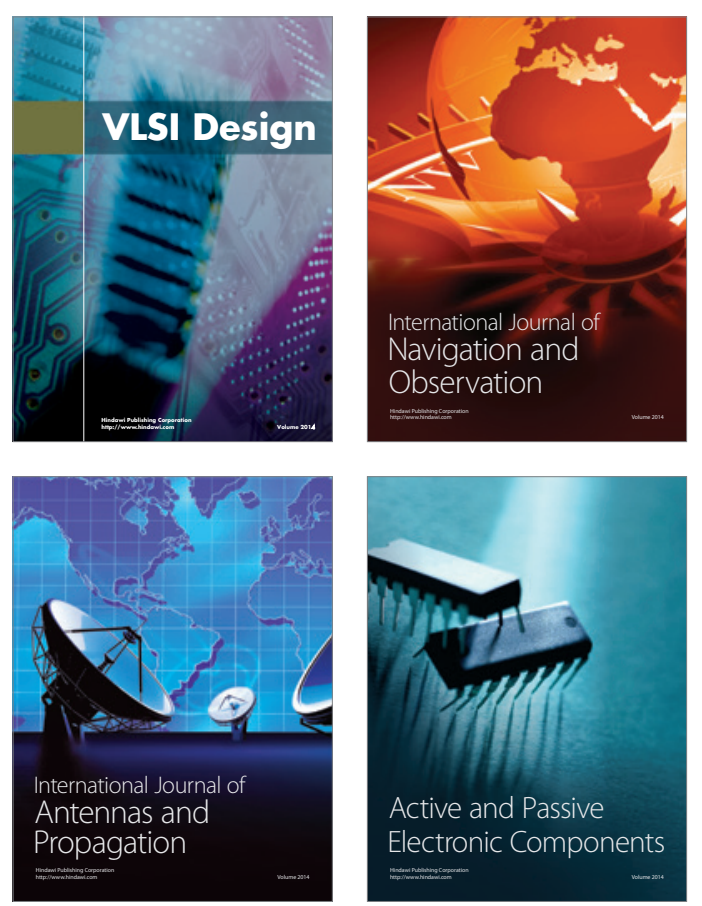
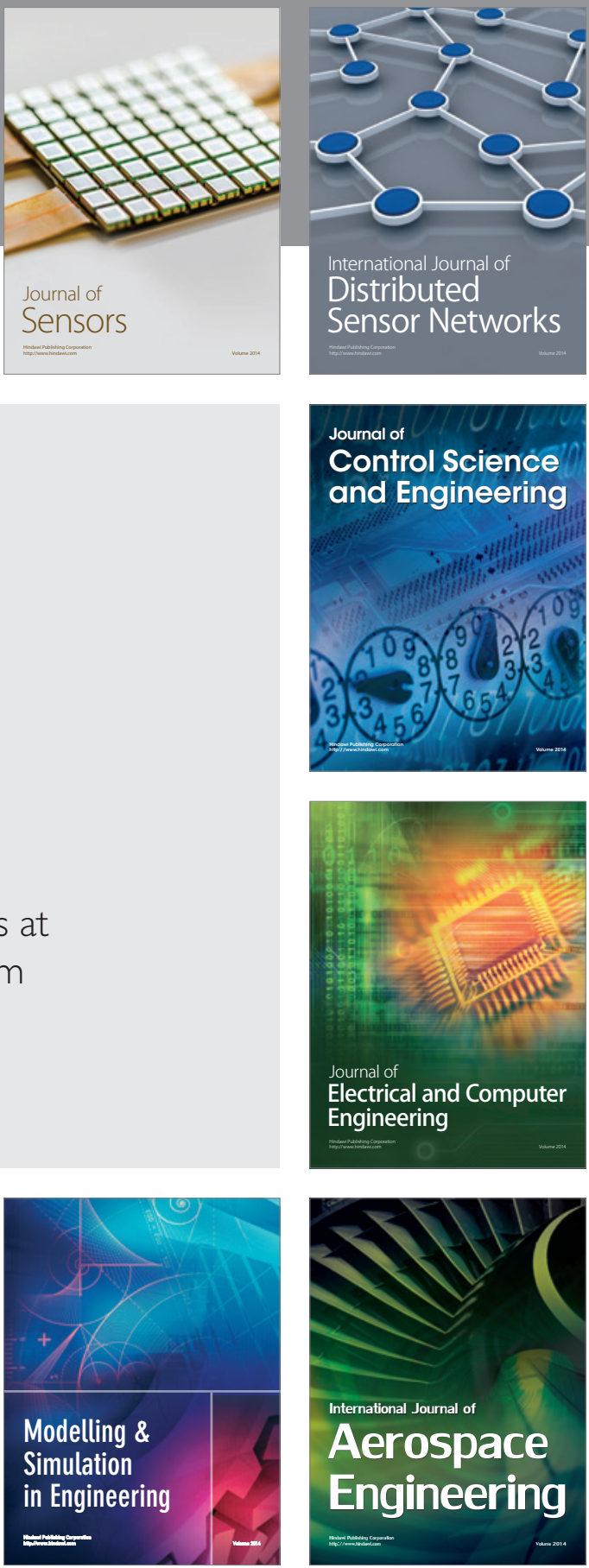

Journal of

Control Science

and Engineering
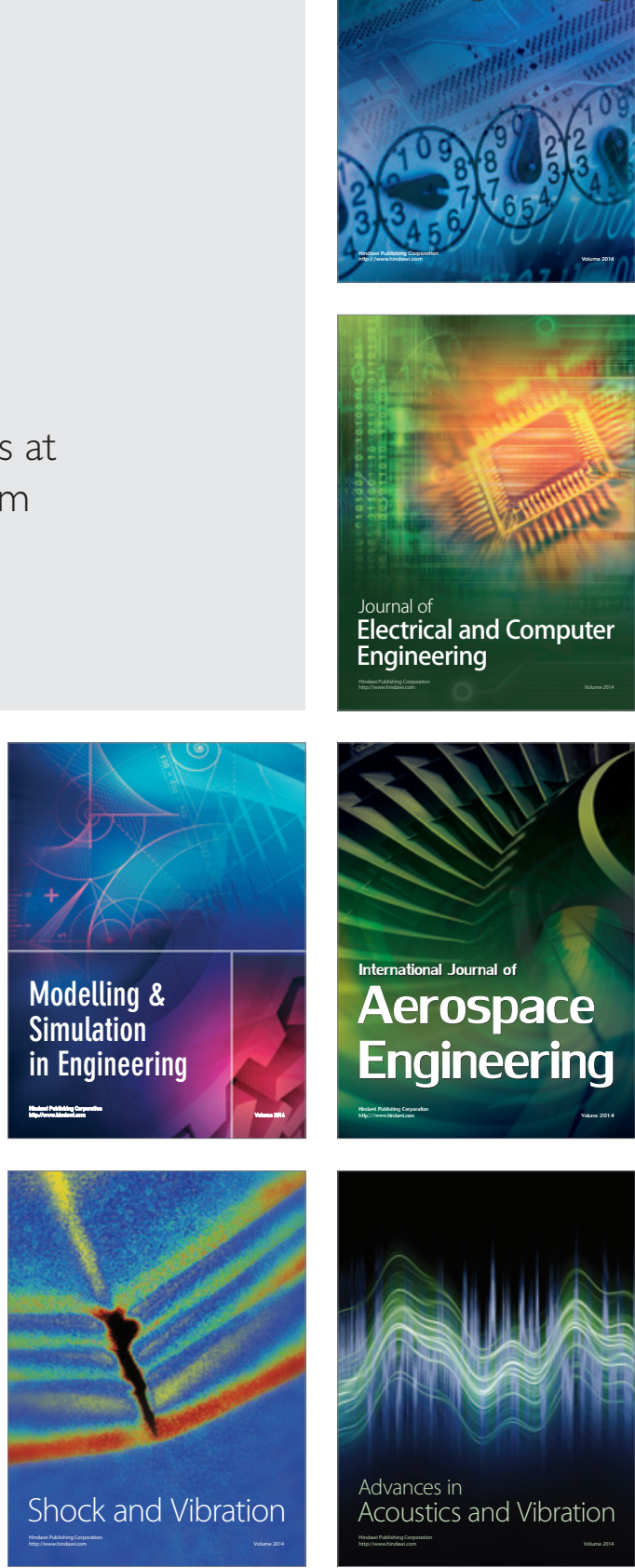